\title{
Operating Cost for Optimal Performance of 100MW Gas Turbine Unit of Ughelli Power Plant
}

\author{
Ugwuoke Philip Emeka ${ }^{1}$, Obodeh Otunuya ${ }^{2}$ \\ ${ }^{1}$ Mechanical Engineering Department, Petroleum Training Institute, Effurun, Nigeria \\ ${ }^{2}$ Mechanical Engineering Department, Ambrose Alli University, Ekpoma, Nigeria
}

\section{Email address:}

ugwuokeemeka@gmail.com (U. P. Emeka)

\section{To cite this article:}

Ugwuoke Philip Emeka, Obodeh Otunuya. Operating Cost for Optimal Performance of 100MW Gas Turbine Unit of Ughelli Power Plant. American Journal of Electrical Power and Energy Systems. Vol. 6, No. 6, 2017, pp. 88-93. doi: 10.11648/j.epes.20170606.12

Received: July 11, 2017; Accepted: August 7, 2017; Published: November 15, 2017

\begin{abstract}
The operating cost for optimal performance of 100MW Delta IV gas turbine unit of Ughelli power plant was determined using optimum operating parameters and exergoeconomics. The optimizatioon tool is an evolutionary algorithm known as Genetic Algorithm (GA). The computer application used in this work is written in Matlab (Version 2011b) programming language. Eight optimal operating parameters of the plant were involved; compressor inlet temperature $\left(\mathrm{T}_{1}\right)$, compressor pressure ratio $\left(r_{p}\right)$, compressor isentropic efficiency $\left(\eta_{i c}\right)$, turbine isentropic efficiency $\left(\eta_{i t}\right)$, turbine exhaust temperature $\left(\mathrm{T}_{4}\right)$, air mass flow rate $\left(\mathrm{m}_{\mathrm{a}}\right)$, fuel mass flow rate $\left(\mathrm{m}_{\mathrm{f}}\right)$ and fuel supply temperature $\left(\mathrm{T}_{\mathrm{f}}\right)$. Eight decision variables were optimally adjusted by the Genetic Algorithm (GA) to minimize the objective function. An objective function representing the total operating cost of the plant was defined in terms of per hour as sum of operating cost (relating to the fuel consumption), rate of capital cost (relating to capital investment and maintenance expenses), and rate of exergy destruction cost. The optimal values of the decision variables (constraints) were obtained by minimizing the objective function. The GA optimal results obtained were $m_{a}=530 \mathrm{~kg} / \mathrm{s}, m_{f}=7.00 \mathrm{~g} / \mathrm{s}$. The GA operating cost and the component GA optimum results for exergy destruction cost rate and capital investment cost rate required to sustain optimum performance were obtained. The operating cost $\left(\dot{C}_{\mathrm{f}}\right)$, cost of exergy destruction rate $\left(\dot{C}_{D}\right)$ and capital investment cost rate $\left(\mathrm{Z}_{\mathrm{K}}\right)$ for the compressor, combustion chamber and turbine are: $\left(\dot{C}_{\mathrm{f}}\right)=\$ 244.72$ per hour giving a variation of $-0.57 \%, \dot{C}_{D \mathrm{c}}=\$ 87,728.32$ per hour giving a variation of $+13.59 \%,\left(\dot{\mathrm{Z}}_{C}\right)=\$ 936,016.00$ per hour giving a variation of $-37.6 \%,\left(\dot{C}_{\mathrm{DCC}}\right)=\$ 470,288$ per hour, a variation of $-88.73 \%$, $\dot{\mathrm{Z}}_{\mathrm{CC}}=\$ 93,160.8$ per hour, a variation of $+305.6 \%, \dot{C}_{\mathrm{Dt}}=\$ 144,278.4$ per hour, a variation of $-84.31 \%, \dot{\mathrm{Z}}_{\mathrm{t}}=\$ 1,428,252.8$ per hour a variation of $+160.1 \%$. These variations were in relation to base results.
\end{abstract}

Keywords: Operating Cost, Optimal Performance, Optimization, Exergoeconomic, Genetic Algorithm

\section{Introduction}

There is a need to ensure that a given engineering system is performing at the optimal level. This is necessary in many engineering applications since efficiency means cost saved and performance maximized. This is the preferred operating condition for any system and also an important criterion to be considered at the design level of any engineering system nowadays [1]

This research uses exergy analysis, a method that uses the conservation of mass and conservation of energy principles together with the second law of thermodynamics for the design and analysis of thermal systems [2]. Genetic
Algorithm was used to minimize the exergy destruction by optimally adjusting the operating parameters. Genetic Algorithm as an optimization tool works based on Charles Darwins theory of evolution (survival of the fittest). Genetic algorithm was originally designed as simulator but has proven to be a robust optimization technique [3], [4]

Genetic algorithm uses two operators to generate new solutions from existing ones: crossover and mutation. The crossover operator is the most important operator of GA. In crossover, two chromosomes called parents are combined to form new chromosomes, called off-springs. The parents are 
selected among the existing chromosomes in the population with preference to fitness. This enables the off-springs to inherit good genes making them better than their parents. By iteratively applying the crossover operator, genes of good chromosomes are expected to appear more frequently in the population, eventually leading to convergence to an overall good solution. The mutation operator introduces random changes into the characteristics of the chromosomes. The aim of mutation is to introduce new genetic material into existing individual; that is, to add diversity to the genetic characteristics of the population. The population which is created randomly at the onset is called initial population. The size of this population may vary from several tens of chromosomes (strings) to several thousands. The criterion applied in determining an upper bound for the size of population, that is further increase does not result in improvement of near-optimal solution. The upper bound for each problem is determined after some test runs. For most applications, the best population size lies within the limits of $100-1000$ strings [3] [4]. On the basis of the optimality (measure of goodness) value, an objective function value or fitness value is assigned to each string. This fitness usually set as the amount of optimality of each string in the population divided by the average population optimality. Effort is always made to ensure that the fitness value is a positive number [3]. It is possible that a certain string does not reflect an allowable condition. For such a case, the fitness of the string is penalized with a very low value, indicting in such a way to the GA that it is not a good string. Similarly, other constraints may be implemented in the GA. The "operators", which are kinds of population transformation devises, are applied to the population. As a result of these operators, a new population is created, that will hopefully consist most optimal strings. The old population is replaced by new one. A predefined stopping criterion, usually maximum number of generation $\mathrm{s}$ to be performed by the GA is checked. If the criterion is not satisfied, a new generation is started, otherwise, the GA terminates.

The objective this study is to evaluate the operating cost for optimal performance of 100MW Gas Turbine Power Plant using GA to minimize the exergy destruction cost rate by optimally adjusting the operating parameters.

\section{Materials and Method}

The data used for this analysis are real time values recorded in the station's operational log book for the period of January 2005 - December 2014[5] for 100MW Delta IV gas turbine at various state points. These recorded values of the parameters were taken in the station every one hour interval for twenty four hours (i.e. daily). Then, the daily, monthly and yearly average values of the parameters were calculated using the EXCEL statistical tool. This exercise is carried out for ten consecutive years. The analysis was carried out with GA tool box in Matlab (Version 2011b). Figure 1 shows the schematic diagram of the power plant demonstrating all its relevant components.
In analysis of the plant, the optimum operating parameters of the plant [6] as shown in table 1 below and exergoeconomic principles were used.

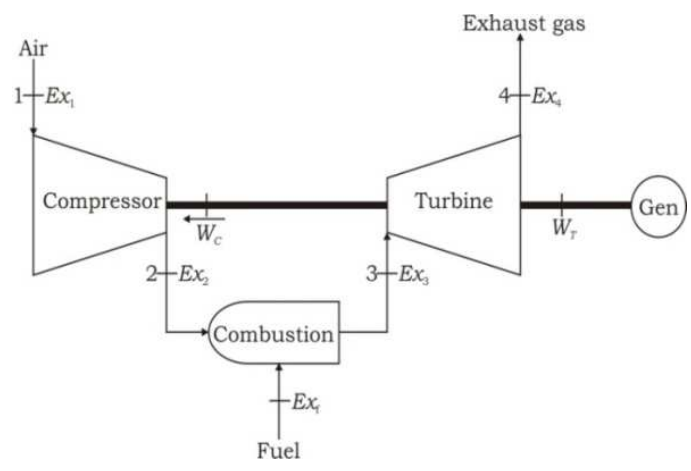

Figure 1. Schematic diagram of the plant.

Table 1. Optimum Operating Parameters of Delta iv power plant

\begin{tabular}{ll}
\hline Property & Value \\
\hline Ambient Temperature, $\mathrm{T}_{1}$ & $300 \mathrm{~K}$ \\
Compressor outlet temperature, $\mathrm{T}_{2}$ & $590 \mathrm{~K}$ \\
Temperature of the fuel $\mathrm{T}_{\mathrm{f}}$ & $298.15 \mathrm{~K}$ \\
Turbine inlet temperature, $\mathrm{T}_{3}$ & $1481.8 \mathrm{~K}$ \\
Turbine outlet temperature, $\mathrm{T}_{4}$ & $1000 \mathrm{~K}$ \\
Compressor inlet pressure, $\mathrm{P}_{1}$ & $1.013 \mathrm{bar}$ \\
Compressor outlet pressure, $\mathrm{P}_{2}$ & $9.89 \mathrm{bar}$ \\
Compressor pressure ratio, $r_{p}$ i.e. $\frac{\mathrm{p}_{2}}{\mathrm{p}_{1}}$ & 9.76 \\
Compressor isentropic efficiency, $\eta_{i c}$ & $86 \%$ \\
Turbine isentropic efficiency, $\eta_{i t}$ & $89 \%$ \\
Mass flow rate of fuel, $\dot{m}_{f}$ & $7.00 \mathrm{~kg} / \mathrm{s}$ \\
Inlet mass flow rate of air, $\dot{m}_{a}$ & $530 \mathrm{~kg} / \mathrm{s}$ \\
Power output, $\dot{W}_{n e t}$ & $107.48 \mathrm{MW}$ \\
\hline
\end{tabular}

\subsection{Exergoeconomic Principles}

The capital investment cost rates for the components were determined based on the modeling expression recommended by [7]. Using the capital recovery factor $(C R F(i, n))$ and present worth factor $(P W F(i, n))$, the annual levelized cost may be written as:

$$
\dot{\mathrm{C}}=P E C-(S V) P W F(i, n) C R F(i, n)
$$

Where $\quad S V=0.1 P E C, C R F(i, n)=i /[1-(1+$ $\left.i)^{-n}\right], P W F(i, n)=(1+i)^{-n}$,

And $P E C$ is the purchased-equipment cost. Equations for calculating the purchased-equipment costs for the components of the gas turbine power plant [10] are:

For the Compressor, we have

$$
P E C_{a c}=\left(\frac{71.1 m_{a}}{0.9-\eta_{i c}}\right)\left(\frac{P_{2}}{P_{1}}\right) \ln \left(\frac{P_{2}}{P_{1}}\right)
$$

For the Combustion Chamber, we have

$$
P E C_{c c}=\left[\frac{46.08 m_{a}}{0.995-\frac{P_{3}}{P_{2}}}\right]\left[1+\exp \left(0.018 T_{3}-26.4\right)\right]
$$

For the Turbine, we have 


$$
P E C_{g t}=\left(\frac{479.34 m_{g}}{0.92-\eta_{i t}}\right) \ln \left(\frac{P_{3}}{P_{4}}\right)\left[1+\exp \left(0.036 T_{3}-54.4\right)\right](4)
$$

Dividing the levelized cost by 8000 annual operating hours (about one month in a year the power plant will be off for maintenance) [8], we obtain the capital cost rate for the $\mathrm{k}^{\text {th }}$ component of the plant:

$$
\dot{\mathrm{Z}}_{k}=\left(\frac{\emptyset_{k} \dot{\mathrm{C}}_{k}}{8000}\right)
$$

The maintenance cost is taken into consideration through the factor $\phi_{k}=1.06$ for each plant component whose expected life is assumed to be 15 years and the interest rates is $14 \%$ [9]. The number of hours of plant operating per year and the maintenance factor utilized in this study are the typical numbers employed in standard exergoeconomic analysis [10]

The formulations of cost balance for each component and the required auxiliary equations are:

For the compressor, we have

$$
\dot{\mathrm{C}}_{2}=\dot{\mathrm{C}}_{1}+\dot{\mathrm{C}}_{W c}+\dot{\mathrm{Z}}_{c}
$$

where the subscripts $w_{c}$ denotes the power input to the compressor.

For the Combustion Chamber, we have

$$
\dot{\mathrm{C}}_{3}=\dot{\mathrm{C}}_{2}+\dot{\mathrm{C}}_{f}+\dot{\mathrm{Z}}_{c c}
$$

For the Turbine, we have

$$
\begin{gathered}
\dot{\mathrm{C}}_{4}+\dot{\mathrm{C}}_{W c}+\dot{\mathrm{C}}_{W t}=\dot{\mathrm{C}}_{3}+\dot{\mathrm{Z}}_{t} \\
\frac{\dot{\mathrm{C}}_{3}}{\dot{\mathrm{E}}_{3}}=\frac{\dot{\mathrm{C}}_{W_{t}}}{W_{t}}
\end{gathered}
$$

Where $W_{t}$ denotes the net power generated by the turbine. Auxiliary equation (9) is written assuming the same unit cost of incoming fuel and outgoing exergy streams. A zero unit cost is assumed for air entering the compressor (i.e. $\dot{C}_{1}=0$ ). Additional auxiliary equation is formulated assuming the same unit cost of exergy for the net power output of the system and power input to the compressor:

$$
\frac{\dot{\mathrm{C}}_{W_{t}}}{W_{t}}=\frac{\dot{\mathrm{C}}_{W_{C}}}{W_{C}}
$$

The information of the cost streams help in exergoeconomic evaluation of the system. In exergoeconomic evaluation of thermal systems, certain quantities, known as exergoeconomic variables, play an important role. These are the average unit cost of fuel $\left(c_{F, k}\right)$, average unit cost of product $\left(c_{P, k}\right)$, the cost rate of exergy destruction $\left(\dot{C}_{D, k}\right)$, and the exergoeconomic factor $\left(f_{k}\right)$.

Mathematically, these are expressed [11] as:

$$
\begin{aligned}
c_{F . k} & =\frac{\dot{\mathrm{C}}_{F . k}}{\dot{\mathrm{E}}_{F . k}} \\
c_{P . k} & =\frac{\dot{\mathrm{C}}_{P . k}}{\dot{\mathrm{E}}_{P . k}} \\
\dot{\mathrm{C}}_{D . K} & =c_{F . K} \dot{\mathrm{E}}_{D . K}
\end{aligned}
$$

$$
f_{k}=\frac{\dot{\mathrm{Z}}_{k}}{\dot{\mathrm{Z}}_{k}+\dot{\mathrm{C}}_{D \cdot k}}
$$

Exergy costing balances (exergoeconomic balances) were carried out for each component. The exergy cost balance consists of operating cost rate (fuel cost rate), capital cost rate and product cost rate.

The cost balance equation is given as;

$$
\dot{\mathrm{Z}}_{K}+\sum \dot{\mathrm{C}}_{F, K}=\sum \dot{\mathrm{C}}_{P, K}
$$

\subsection{Economic Constraints}

For a component receiving a heat transfer and generating power, cost balance equation may be written as [12]:

$$
\sum_{e} \dot{\mathrm{C}}_{e, K}+\dot{\mathrm{C}}_{W, K}=\dot{\mathrm{C}}_{Q, K}+\sum_{i} \dot{\mathrm{C}}_{i, K}+\dot{\mathrm{Z}}_{K}
$$

where $\dot{C}$ denotes a cost rate associated with an exergy stream and the variable $\dot{Z}$ represents non-exergetic costs.

\subsection{The Objective Function}

The objective function expresses total cost rate of the plant in terms of naira per unit time.

$$
\text { i. e. } O F=\dot{\mathrm{C}}_{\text {Ptotal }}=\dot{\mathrm{C}}_{f} m_{f} L H V+\sum \dot{\mathrm{Z}}_{K}+\sum \dot{\mathrm{C}}_{D, K}
$$

The thermal system requires two conflicting objectives; one being increase in exergetic and energy efficiencies and the other is decrease in product cost to be satisfied simultaneously. The maximization of exergetic efficiency means minimization of exergy destruction cost. Thus, the objective fucntion becomes a minimization problem. The objective function for this problem is defined as to minimize a total cost function $\dot{\mathrm{C}}_{\text {Ptotal }}$ which is modelled as:

$$
\dot{\mathrm{C}}_{\text {Ptotal }}=\dot{\mathrm{C}}_{\text {Ftotal }}+\sum \dot{\mathrm{Z}}_{K}
$$

In this optimization, compressor pressure ratio $\left(r_{P}\right)$, compressor isentropic efficiency $\left(\eta_{i c}\right)$, turbine isentropic efficiency $\left(\eta_{i t}\right)$, combustion product temperature $\left(T_{3}\right)$, air mass flow rate $\left(m_{a}\right)$, fuel mass flow rate $\left(m_{f}\right)$, temperature of the fuel $\left(T_{f}\right)$ are taken as decision variables.

The stopping conditions used for solving the optimization problem are the maximum number of generations and cumulative function tolerance, which are shown in Table 3.

Table 3. Stop criteria for the optimization algorithm.

\begin{tabular}{ll}
\hline Stop criterion & Value \\
\hline Number of generation & 300 \\
Function tolerance & $1 \times 10^{-7}$ \\
\hline
\end{tabular}

\subsection{Genetic Algorithm Optimization}

The optimization is done using Non-Dominated Sorting Genetic Algorithm (NSGA) proposed by [13]. The algorithm eliminates higher computational complexity, lack of elitism and the requirement for specifying sharing parameter. The developed GA code selects the decision variables in such a way to decrease the objective function. The flowchart of the algorithm is shown in Figure 2. The optimization code was 
written in MATLAB programming language. The optimal values of the decision variables (constraints) were obtained

by minimizing the objective function.

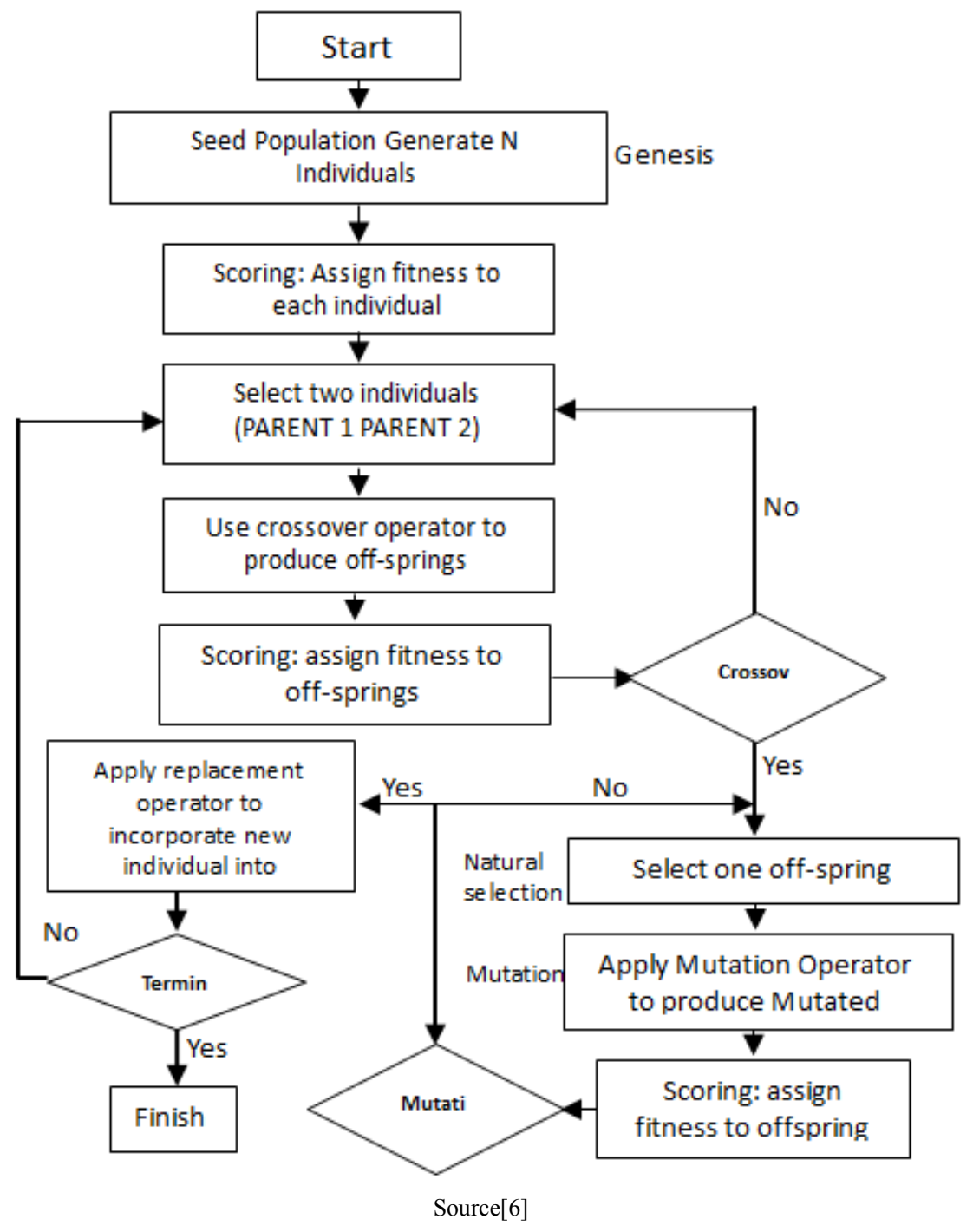

Figure 2. Flowchart for GA optimization.

\section{Results and Discussion}

In this study, both optimization and exergoeconomic analysis of Delta IV Ughelli power plant were performed.
The objective function which is given to evolutionary algorithm (i.e. Genetic Algorithm) is considered here. The objective function is a summation of three important parts; operational cost rate, capital investment cost rate and exergy destruction cost rate.

Table 4. Comparison of the base (measured) data with the optimum result.

\begin{tabular}{llll}
\hline Property & Base data & GA Optimum & Variation (\%) \\
\hline Compressor pressure ratio, $r_{p}$ & 10.47 & 9.76 \\
Compressor isentropic efficiency, $\eta_{i c}(\%)$ & 88 & 86.4 \\
Turbine isentropic efficiency, $\eta_{i t}(\%)$ & 89 & 89.12 & -6.8 \\
Turbine inlet temperature, $T_{3}(\mathrm{~K})$ & $1,238.5$ & $1,481.8$ \\
Mass flow rate of air, $\dot{m}_{a}(\mathrm{~kg} / \mathrm{s})$ & 427.00 & 530 & +0.13 \\
Mass flow rate of fuel, $\dot{m}_{f}(\mathrm{~kg} / \mathrm{s})$ & 7.04 & 7.00 & +10.97 \\
\hline
\end{tabular}

Table 5 shows that the exergy destruction cost rate for the components for the base and GA optimum. The exergy destruction cost rate increases slightly from $\$ 77,231.20$ per hour for measured to $\$ 87,728.32$ per hour for optimum result in the compressor, a variation of $13.59 \%$. The increase in exergy destruction cost rate is due to increase in exergy destruction rate for optimum results. 
Table 5. Comparison of the measured(base) exergy destruction cost rate with the optimum result.

\begin{tabular}{|c|c|c|c|}
\hline Exergy destruction cost rate & Base ( $/$ hr) & GA Optimum ( $/$ /hr) & Variation (\%) \\
\hline Exergy destruction cost rate in the compressor & $77,231.20$ & $87,728.32$ & +13.59 \\
\hline Exergy destruction cost rate in the combustion chamber & $4,171,488$ & $470,288.00$ & -88.73 \\
\hline Exergy destruction cost rate in the turbine & $226,878.24$ & $144,278.4$ & -36.41 \\
\hline
\end{tabular}

In the combustion chamber, the exergy destruction cost rate decreases from $\$ 4,171,488$ per hour for measured to $\$ 470,288.00$ for optimum results. This gives a variation of $88.73 \%$. This is due to large decrease in exergy destruction for optimum results in the combustion chamber. The total exergy destruction in the plant decreases from $¥ 4,475,597.44$ for measured to $\$ 702,294.72$ for optimum results, resulting to a variation of $-84.31 \%$ for the total cost of exergy destruction. This is due to minimization of total exergy destruction by increasing the fraction of capital investment cost for repair, refurbishment and replacement of parts of components

Table 6 shows capital investment cost rate of the components which means initial purchase cost less depreciation cost plus cost of maintenance for measured (base) and GA optimum results.

Table 6. Comparison of the measured (base) capital investment cost rate with the optimum result.

\begin{tabular}{|c|c|c|c|}
\hline capital investment cost rate & Base $(\mathrm{N} / \mathrm{hr})$ & GA Optimum ( $\mathbf{N} / \mathbf{h r})$ & Variation (\%) \\
\hline Capital investment cost rate in the compressor & $1,500,057.6$ & $936,016.00$ & -37.6 \\
\hline Capital investment cost rate in the combustion chamber & $22,964.16$ & $93,160.8$ & +305.6 \\
\hline Capital investment cost rate in the turbine & $548,872.00$ & $1,428,252.8$ & +160.1 \\
\hline
\end{tabular}

The results invariably show that the fraction of capital investment cost meant for repair, refurbishment and replacement of bearings and seals, compressor blades and the exhaust system of the compressor decrease from $\$ 9003.46$ per hour for measured to $\$ 56,160.96$ per hour for optimum results, a variation of $-37.6 \%$. Six percent $(6 \%)$ of capital investment cost is used as maintenance cost in this study which is employed in standard exergoeconomic analysis [7]. The reduction in the fraction of capital investment is due to slight increase in exergy destruction as shown in table of results. The increase in exergy destruction results to decrease in the value of $T_{2}$ from $632 \mathrm{~K}$ for measured to $590 \mathrm{~K}$ for optimum results and consequent reduction in pressure ratio and isentropic efficiency. The drop in $T_{2}$ reduces thermal tension in the component parts thereby reducing fraction of capital investment cost for maintenance.

Table 6 also shows an increase in the fraction of capital investment cost for the combustion chamber meant for repair, refurbishment and parts replacement of transition pieces, combustion liners, end caps, fuel nozzle assemblies, cross fire tubes[14] from $\$ 1,377.85$ per hour for measured to $\$ 5,589.65$ per hour for optimum result, leading to a variation of $305.6 \%$. The fraction of capital investment cost for maintenance increase in the combustion chamber is due to large exergy destruction rate caused by process irreversibilities.

It is also observed in Table 6 that the fraction of capital investment cost for the turbine meant for repair, refurbishment and parts replacement; turbine nozzles, turbine stationary shrouds and turbine buckets in the turbine [14] increases from $\$ 32,932.32$ per hour for measured to $\$ 85,695.17$ per hour for optimum result, a variation $160.1 \%$. The high investment cost is to reduce exergy destruction rate caused by irreversibilities.

\section{Conclusion}

Exergoeconomic optimization and analysis of operating parameters have been performed on Delta IV Ughelli Power Plant using Genetic Algorithm. Two objective functions were involved in the optimization process; thermodynamic (e.g. maximum efficiency or minimum fuel consumption) and economic (e.g. minimum cost per unit of time).

Optimized values revealed that component's cost rate of exergy destruction in the combustion chamber decreased by a variation of $-88.73 \%$ while that of the turbine decreased by a variation of $-36.41 \%$. However, that for the compressor increased by a variation of $13.59 \%$. The component's capital investment cost rate in the combustion chamber increases by a variation of $305.6 \%$ and that of the turbine increased by a variation of $160.1 \%$. Anyway, that of the compressor decreased by a variation of $-37.6 \%$. These are the financial implications of sustaining the optimum performance of the various components via routine maintenance, refurbishment and spare parts replacement.

The results above show that the fuel consumption decreased from measured (base) result to GA optimum result by a variation of $-.57 \%$. The total capital investment cost rate increased from the base result to GA optimum result by a variation of $18.61 \%$. The total exergy destruction cost rate decreased from the measured (base) result to GA optimum result by a variation of $-84.31 \%$.

\section{Notations}

$\mathrm{Cf}=$ Cost of fuel per unit energy $(\mathrm{N} / \mathrm{MJ})$

$\mathrm{Q}_{\mathrm{v}}=$ Lower Heating Value $(\mathrm{kJ} / \mathrm{kg})$

$\dot{\mathrm{C}}_{\mathrm{f}}=$ Fuel cost rate $(\mathrm{A} / \mathrm{hr})$

$\dot{\mathrm{Z}}_{\mathrm{K}}=$ Annual levelized cost rate of components ( $\left.\# / \mathrm{hr}\right)$

$\dot{\mathrm{C}}_{\mathrm{K}}=$ Annual levelized cost rate of components ( $\left.\mathrm{N} / \mathrm{hr}\right)$

$\phi=$ Maintenance factor.

$\mathrm{N}=$ Annual number of operating hours (hrs)

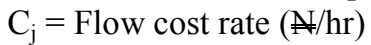

$\mathrm{Cj}=$ Unit cost of exergy (N/MJ) 
$\mathrm{r}_{\mathrm{P}}=$ Pressure ratio.

$\eta_{\text {ic }}=$ Isentropic efficiency of the compressor (\%)

$\eta_{\text {it }}=$ Isentropic efficiency of the gas turbine $(\%)$

$\mathrm{S} . \mathrm{V}=$ Salvage value.

N $=$ Naira.

$\mathrm{T}_{1}=$ Compressor input temperature $(\mathrm{K})$

$\mathrm{T}_{2}=$ Compressor output temperature $(\mathrm{K})$

$\mathrm{T}_{3}=$ Combustion chamber output temperature $(\mathrm{K})$

$\mathrm{m}_{\mathrm{a}}=$ Air mass flow rate $(\mathrm{kg} / \mathrm{s})$

$\mathrm{m}_{\mathrm{f}}=$ Fuel mass flow rate $(\mathrm{kg} / \mathrm{s})$

$\mathrm{PWF}=$ Present worth factor.

$\mathrm{CRF}=$ Capital recovery factor.

$\mathrm{PEC}=$ Purchased equipment cost.

$\mathrm{T}_{\mathrm{o}}=\mathrm{T}_{\text {ref }}=$ Standard reference temperature $(\mathrm{K})$

$\mathrm{P}_{\text {ref }}=$ Standard reference pressure (bar)

$\mathrm{T}_{\mathrm{f}}=$ Temperature of fuel supplied $(\mathrm{K})$

$\mathrm{W}_{\mathrm{t}}=$ Rate of work output from the turbine (MW).

$\mathrm{W}_{\mathrm{c}}=$ Rate of work input to the compressor (MW).

$\mathrm{c}_{\mathrm{wt}}=$ Unit cost of turbine work ( $\left.\# / G J\right)$.

$\mathrm{c}_{\mathrm{wc}}=$ Unit cost of compressor work ( $\left.₫ / G J\right)$.

$\dot{\mathrm{C}}_{\mathrm{wt}}=$ Total cost rate of turbine work output ( $\mathbb{A} / \mathrm{hr}$ ).

$\dot{\mathrm{C}}_{\mathrm{wc}}=$ Total cost rate of compressor work $(\mathrm{N} / \mathrm{hr})$.

$\$ / \mathbb{N}=$ Exchange rate @ November, 2016=304

$\dot{\mathrm{C}}=$ Exergy cost rate $(\mathbb{N} / \mathrm{hr})$.

$\mathrm{c}=$ Unit cost of exergy $(\$ / \mathrm{GJ}$ or $\$ / \mathrm{kWh})$.

$\mathrm{f}=$ Exergoeconomic factor.

$\dot{\mathrm{C}}_{\mathrm{T}}=$ Total cost of running the plant per hour ( $\left.\mathbb{A} / \mathrm{hr}\right)$.

$\mathrm{GA}=$ Genetic algorithm

$\mathrm{OF}=$ Objective function.

$\dot{\mathrm{C}}_{\text {ptotal }}=$ Total cost rate of the plant.

\section{References}

[1] Lee, K. O., Parthiban, A., Ong, K. E., Quadir, G. A., Seetharamu, K. N., Aswatha, N. P. A., Abdullah, M. Z., Azid, I. A. and Zainal, A. Z. A. (2013). Optimization of Thermodynamic Cycles for Gas Turbines using Genetic Algorithms, Working Paper, School of Mechanical Engineering, Universiti Sains Malaysia (USM), Engineering Campus, Malaysia.
[2] Bejan, A., Tsatsaronis, G. and Moran, M. (1996). Thermal Design and Optimization. Wiley, New York.

[3] Coley, A. D. (1999); An Introduction to Genetic Algorithms for Scientists and Engineers, $2^{\text {th }}$ Edition, World Scientific Publishing Co. Pte. Ltd, Singapore, 211pp.

[4] Malhotra, R.; Singh, N. and Singh, Y. (2011); Genetic Algorithms: Concepts, Design for Optimization of Process Controllers, Computer and Information Science, Vol. 4, No. 2, pp. 39-54.

[5] PHCN (2015); Ughelli Power Plant Logbook, Ughelli, Delta State, Nigeria.

[6] Obodeh, O. and Ugwuoke, P. E. (2017); Optimal Operating Parameters Of $100 \mathrm{mw}$ Delta Iv Ughelli Gas Turbine Power Plant Unit, in press.

[7] Moran, M. J. and Shapiro, H. (2000). Fundamentals of Engineering Thermodynamics, $4^{\text {th }}$ Edition, Wiley, New York.

[8] Khosravi, A.; Gorji-Bandpy, M. and Fazelpour, F. (2014); Optimization of a Gas Turbine Cycle by Genetic and PSO Algorithms, Journal of Middle East Applied Science and Technology (JMEAST), Issue 21, pp. 706-711.

[9] Emefiele, G. (2016). MPR: Banks Raise Interest Rates on Existing Loans. Punch Newspapers, July 29.

[10] Moran, M. J. (1982). Availability Analysis; A Guide to Efficient Energy Use, USA: Prentice Hall, Englewood Cliffs, N. J.

[11] Ebadi, M. and Gorji-Bandpy, M. (2005). Exergetic Analysis of Gas Turbine Plants. International Journal of Exergy 2 (4), 31-39.

[12] Gorji-Bandpy, M. and Goodarzian, H. (2011). Exergoeconomic Optimization of Gas Turbine Power Plant Operating Parameters Using Genetic Algorithm: A Case Study. $J$ Thermal Science, 15, 43-54.

[13] Srinivas, N. and Deb, K. (2002); Multi-Objective Optimization using Non-Dominated Sorting in Genetic Algorithms, Journal of Evolutional Computation, Vol. 2, No. 3 , pp. 221-248.

[14] Jomison Janawitz, James Masso and Christopher Childs (2015). Heavy-Duty Gas Turbine Operating and Maintenance Consideration Ger 3620M. GE Power and Water, Atlanta, Georgia, February. 